\title{
EXISTE MEDO DE IR À ESCOLA?
}

\author{
Graziela Sapienza* \\ Teresa Helena Schoen ${ }^{*}$
}

As dificuldades escolares são alvos frequentes de pesquisas e discussões. Estão incluídos nesse tema diferentes problemas que podem levar a criança ou o adolescente a abandonar a escola, como inadaptação, relacionamento inadequado com pares e professores, reprovação, dificuldades específicas de aprendizagem, recusa escolar, absenteísmo, problemas de comportamento, desempenho abaixo das expectativas de pais, das expectativas dos professores e dos padrões da escola e transtornos psicológicos.

Profissionais da área médica tendem a atribuir às dificuldades escolares causas como desnutrição ou disfunções neurológicas (Gutierrez, 1994). A tentativa de identificar a dificuldade escolar como consequência de uma condição médica pode, por um lado, querer isentar a escola de possíveis erros ou deficiências; mas, por outro lado, atribui esse problema às condições sócio-econômicas, ou mesmo a uma característica intrínseca da criança. Justificar a dificuldade escolar da criança com uma causa orgânica resguarda possíveis questões familiares e escolares que podem ser a real causa e que deveriam ser investigadas mais profundamente. Por outro lado, alguns educadores podem atribuir o "não ir à escola" à preguiça, falta de vontade ou ao fato dos pais serem negligentes e não exigirem a presença na escola dos filhos. Excluídas as questões orgânicas e socioeconômicas, que não são o foco deste artigo, encontramos entre os problemas que levam a criança e o adolescente a abandonarem a escola, alguns transtornos psicossociais, como a fobia escolar.

Tema pouco frequente entre os profissionais de saúde e educação, a fobia escolar é caracterizada basicamente pelo medo de ir à escola. É uma dificuldade que pode trazer consequências negativas para toda a formação do indivíduo, isso porque em nossa sociedade, frequentar o ensino formal é obrigatório e básico para o futuro profissional. Algumas situações escolares aparecem entre as mais frequentes causas de ansiedade e medos em crianças em idade escolar, sendo comuns o medo do fracasso escolar (ex: tirar notas baixas), o medo social (ex. apresentar trabalhos oralmente diante da turma ou fazer perguntas ao professor) e a ansiedade antecipatória, medo que precede à permanência na escola (ex. ansiedade ao arrumar a mochila, fazer o trabalho de uma disciplina ou de esquecer-se de levar algum material importante) (Méndez, Olivares \& Bermejo, 2005).

O objetivo deste artigo é apresentar a fobia escolar aos profissionais de saúde e educação que trabalham com crianças e adolescentes, indicando os critérios diagnósticos, incidência, dificuldades no diagnóstico e tratamentos mais indicados. Medo de ir à escola e fobia escolar serão usados, aqui, como sinônimos para caracterizar a dificuldade da criança ou adolescente em frequentar assiduamente às aulas.

\section{Critérios Diagnósticos}

O medo de ir para a escola é caracterizado por uma ansiedade excessiva relacionada ao afastamento de casa ou de figuras importantes de vinculação. Essa ansiedade está além da esperada para a etapa de desenvolvimento em que o indivíduo se encontra e causa prejuízo no funcionamento social e acadêmico. Esses sintomas devem estar presentes nos últimos seis meses e seu início ocorre em qualquer idade, porém o mais comum é o início antes dos 18 anos de idade (DSM-5, 2013). As crianças e adolescentes com transtorno de ansiedade de separação frequentemente relutam ou se recusam a ir à escola e quando vão podem sentir saudade extrema, chegando a apresentarem queixas somáticas, como

* Pontifícia Universidade Católica do Paraná

** Universidade Federal de São Paulo 
dores abdominais, dor de cabeça, náuseas, vômitos ou sintomas cardiovasculares (palpitações, tontura e sensação de desmaio), esses últimos mais comuns em crianças mais velhas ou adolescentes.

Além disso, quando as crianças não estão em casa ou com as figuras de vinculação, precisam entrar sempre em contato a fim de se certificarem que estão bem. São crianças que telefonam para seus pais muitas vezes ao dia, mesmo quando estão na escola.

Dessa forma, não basta a criança não querer ir para a escola para esse comportamento ser caracterizado como fobia escolar, são necessários também sintomas como uma preocupação excessiva com as figuras de vinculação, medo inapropriado de ficar sozinha, pesadelos envolvendo separação e os sintomas físicos que devem ser observados sempre em conjunto com o medo de ir à escola (CID-10, 1993).

É importante esclarecer que a ansiedade de separação é comum em algumas etapas do desenvolvimento (PAPALIA \& OLDS, 2000). Crianças pré-escolares ou no início da escolarização podem apresentar os sintomas acima descritos, da mesma forma, crianças pequenas podem apresentá-los quando mudam de escola. Entretanto, a adaptação à escola, seja no início da escolarização ou após a mudança de escola, reduz e elimina esses sintomas rapidamente. Em geral, após um mês de aulas a criança não apresentará mais problemas para ir à escola.

Existem alguns casos em que o medo de ir à escola não ocorre por medo de ficar longe dos pais, mas por um medo exagerado de algo relacionado à situação escolar. Nesse caso, fala-se no transtorno de fobia específica ao invés de transtorno de ansiedade de separação e são observados sintomas importantes de ansiedade na presença ou na antecipação da situação fóbica (CID-10, 1993), isto é, durante alguma aula específica, na entrada da escola, no horário de sair para ir à escola, de colocar o uniforme, mas não em qualquer momento em que a criança pode ficar separada dos pais (por exemplo, a hora de dormir).

Para ser caracterizado como fobia específica, o medo de ir à escola deve ser excessivo, persistente, causar ansiedade e ser percebido como irracional ou, no caso de crianças, deve ser considerado pelos responsáveis como exagerado (DSM-5, 2013; Gutierrez, 1994). Essa manifestação de ansiedade deve ser restrita à presença ou proximidade da situação fóbica que, nesse caso, é a escola (CID-10, 1993). Da mesma forma, a proximidade com o estímulo fóbico, que provoca medo, deve ser frequentemente evitada pelo indivíduo. É comum que as crianças com fobia escolar apresentem o medo de ir à escola não só diante da escola (estrutura física), mas também quando percebem que o horário de ir à escola está chegando, por exemplo, quando os pais pedem para que a criança coloque o uniforme ou arrume seus materiais.

Para a compreensão adequada do problema, o profissional (educador, médico, psicólogo) ou mesmo os pais podem observar se a ansiedade vivenciada pela exposição ou antecipação da situação que causa medo pode se transformar em ataque de pânico, assumindo em crianças a forma de choro, imobilidade, ataques de raiva, evitação ou fuga da situação. É fundamental que os profissionais, especialmente os de saúde, investiguem se os sintomas estão interferindo significativamente na rotina normal do indivíduo, em seu funcionamento acadêmico ou em atividades sociais (DSM-5, 2013).

Portanto, é possível dizer que a fobia escolar pode ser um transtorno de ansiedade de separação quando o medo mais importante não é o de ir à escola, mas o de deixar a mãe, o pai ou outra figura importante em casa, acreditando que algo acontecerá com essa pessoa. Se a fobia se caracterizar efetivamente pelo medo de alguma situação escolar - um professor bravo, um colega que zomba, as provas -, aí sim tem- se uma fobia específica e será necessário modificar o ambiente em que a criança ou o adolescente estuda e ensinar novas formas de enfrentar esse ambiente.

\section{Incidência}

A incidência de fobia escolar aumentou muito entre as décadas de 1970 e 1980 . Um estudo realizado por Grünspum (1981) verificou que de 1973 a 1981, o número de casos passou de 03 para 17 em cada 1000 crianças. Esse aumento pode ser decorrente de melhores condições de diagnóstico e aumento na frequência de encaminhamentos. De acordo com esse estudo, a idade de incidência pode variar de 05 a 14 anos de idade, sendo a idade média 08 anos. Não foram observadas diferenças entre os sexos. 
Em estudos realizados na década de 1980 verificaram que a fobia escolar atinge mais meninos do que meninas, normalmente na infância entre $5 \mathrm{e}$ 13 anos, sendo mais comum nos primeiros anos da escolarização (Ajuriaguerra e Marcelli, 1991). Mais tarde, Papalia e Olds (2000) estendem um pouco o período em que aparece a fobia escolar, indo até os 15 anos e destacam que em $80 \%$ dos casos a criança ou o adolescente que apresenta esse tipo de medo costuma ser filho único ou ser o primogênito ou o caçula.

A fobia escolar também aparece com mais frequência em crianças com maiores quocientes de inteligência (Ajuriaguerra \& Marcelli, 1991; Grünspum, 1981). Grünspum (1981) apresenta um estudo realizado por Judge Baker que mostrou que 78,7\% das crianças com fobia escolar apresentam níveis de inteligência acima da média. Esse mesmo trabalho mostrou que existe maior incidência de fobia escolar, devido uma ambição cultural que pode provocar grande ansiedade nos filhos no caso deles não se sentirem ou realmente não serem capazes de atingir os objetivos dos pais.

\section{Características e Dificuldades de Diagnóstico}

Apesar de a literatura indicar que há uma grande incidência de início da fobia escolar nos primeiros anos escolares, o medo de ir à escola pode começar mais tarde, na adolescência ou mesmo na vida adulta, principalmente nas épocas mais marcantes da vida escolar, como as caracterizadas no Brasil na passagem do quinto para o sexto ano do Ensino Fundamental, no início do Ensino Médio ou no ingresso na Educação Superior (Sapienza, Schoen-Ferreira \& Aznar-Farias, 2003). A fobia escolar pode perdurar por toda a vida e muitas vezes permanecer sem tratamento, o que acarreta prejuízos acadêmicos e ocupacionais.

Por isso, o medo da escola deve ser analisado como um conceito amplo que pode envolver as mais diversas situações relacionadas à escola e aos estudos. Um adolescente ou adulto que fracassa no vestibular pode começar a evitar ou sentir ansiedade quando precisa fazer alguma prova. Esse indivíduo acaba perdendo suas ambições acadêmicas e pode ficar prejudicado em seu futuro profissional, pois passará a se esquivar de toda e qualquer situação que o remeta a alguma atividade acadêmica ou intelectual (Sapienza, Schoen-Ferreira \& Aznar-Farias, 2003), principalmente diante de provas (James \& Javaloyes, 2001).

Uma dinâmica familiar peculiar é encontrada na maioria dos casos de fobia escolar. As crianças ou adolescentes são frequentemente muito dependentes da família (Ajuriaguerra \& Marcelli, 1991) ou provêm de famílias muito unidas e afetuosas (Papalia \& Olds, 2000). A mãe costuma ser bastante ansiosa depressiva e até mesmo fóbica. Já o pai parece ser passivo, fraco ou mesmo ausente, seja por divórcio ou morte. A passividade ou a falta do pai, principalmente para os meninos, dificulta a percepção de um modelo adequado da figura paterna e esta criança pode se tornar também passiva e pouco afirmativa, assegurando à mãe o controle sobre a família.

Mães superprotetoras, muitas vezes, tendem a arrumar motivos para manter seus filhos sob sua proteção, impedindo qualquer situação que possa aumentar a independência entre ela e a criança, como ir à escola. Qualquer sinal de um sintoma físico ou mesmo uma mudança no clima pode ser motivo para que seu filho não vá à escola. Desse modo, os próprios pais dificultam a situação de separação, mantendo um relacionamento caracterizado pela necessidade de proximidade física provocando na criança a ansiedade de separação e o aumento na dificuldade de abandonar a casa. Outras vezes, as crianças temem abandonar os pais por acreditarem que algo maligno (morte, doença, incêndio) possa acontecer enquanto estiver fora e, por isso, preferem manter a vigília em casa, garantindo a segurança da família (Grünspum, 1981). Em casos mais extremos, essas crianças trocam o dia pela noite para assim poderem vigiar a casa enquanto os pais estão dormindo. Todas as atitudes dos pais e das crianças podem desencadear a fobia escolar.

A perda de um animal de estimação ou uma enfermidade, situações que tendem a causar ansiedade na criança, também podem dar início à fobia escolar (Papalia \& Olds, 2000). Do mesmo modo, mudanças de ambiente, principalmente de mudanças de casa ou de escola, têm sido consideradas fatores desencadeantes da fobia escolar. Unem-se a esses fatores: conflito entre os pais, doença da mãe 
e rebaixamento da condição financeira com reações maternas violentas (Grünspum, 1981).

Frequentemente a fobia escolar aparece acompanhada de outros problemas. Diferenciar a fobia escolar de outros problemas de comportamento (ansiedade, absenteísmo, recusa escolar) é difícil, mas pode ficar mais fácil se considerarmos a idade em que o transtorno aparece. Ajuriaguerra e Marcelli (1991) e Grünspum (1981) acreditam que a ansiedade de separação aparece apenas na criança bem pequena, muito dependente da família e que ainda não tem experiência escolar, sendo entendido como um sintoma transitório. Porém, é comum que o adolescente ou a criança com fobia escolar tenha apresentado ansiedade de separação anteriormente, mas que não foi diagnosticada.

São comuns as comorbidades com outros tipos de fobias (medo do escuro, agora fobia, fobia social) e de transtorno obsessivo-compulsivo (TOC), com a repetição de comportamentos associados ao contexto escolar, como os que envolvem arrumação do material escolar ou rotina para realizar as tarefas. Também aparecem associados ao medo de ir à escola, comportamentos agressivos e impulsividade, principalmente direcionadas à mãe (Ajuriaguerra \& Marcelli, 1991).

Muitas crianças que apresentam fobia escolar são diagnosticadas também com depressão (Ajuriaguerra \& Marcelli, 1991; Grünspum, 1981). Cerca de $20 \%$ dos casos têm depressão associada, principalmente na pré-adolescência. Crianças fóbicas são tristes e chorosas, mas acabam encobrindo esses comportamentos. É interessante destacar que é comum que um dos pais ou cuidadores dessa criança apresente depressão associada.

O indivíduo com medo de ir à escola usa várias desculpas para se esquivar de ir para a escola e essas desculpas se modificam de acordo com a etapa de desenvolvimento (Gutierrez, 1994). Até os 05 anos é comum que as crianças com fobia escolar apresentem comportamentos que caracterizam birra, principalmente quando estão saindo para irem à escola, com isso, muitas vezes, vencem os pais e acabam ficando em casa. Mais tarde, entre 05 e 07 anos, os ataques de birra se apresentam mais elaborados e a ansiedade pode se tornar somática, ocorrendo vômitos, dores abdominais, cefaléias, enure- se, encoprese, que costumam desaparecer quando a criança ou o adolescente não vai à escola.

$\mathrm{Na}$ adolescência o diagnóstico de fobia escolar também pode ser acompanhado de agressividade e oposição violenta; comportamentos que, como nas crianças, vêem à tona quando o adolescente está chegando até a escola ou mesmo em casa, perto do horário de sair para as aulas (Gutierrez, 1994). Quando o medo toma a forma de ataques de pânicos, vemos algumas crianças ou adolescentes se trancarem no quarto ou ficarem aos prantos. Nesses casos, muitos pais acreditam que isso é apenas uma desculpa para seu filho faltar à escola, quando na verdade já é um sintoma do problema.

Algumas vezes os pais conseguem convencer o filho a ir à escola. Quando isso acontece, apesar de entrar na escola, a criança ou o adolescente acaba arrumando um jeito de sair da sala e ligar para os pais ou mesmo fugir para casa (Ajuriaguerra \& Marcelli, 1991). Nesse ponto parece importante diferenciarmos a fobia escolar do absenteísmo: enquanto o fóbico foge da escola para voltar para casa, o cabulador vai fazer algo que acredita ser mais divertido do que assistir às aulas. Apesar de em ambos os casos a criança ou adolescente não querer ir à escola, no primeiro caso a criança normalmente nem chega a sair de casa e tende a passar o horário das aulas em casa, preocupado em não deixar que os outros saibam que ele não vai à escola; já no absenteísmo, a criança vai até a escola, mas não chega a entrar, ficando, muitas vezes na rua até o horário de voltar para casa ou quando entra dá um jeito de sair durante o período em que deveria estar em aula para fazer algo que ela considera mais agradável (Grünspum, 1981). O absenteísmo não é acompanhado de ansiedade ou de angústia (Ajuriaguerra \& Marcelli, 1991), já que a criança ou o adolescente deixa a casa normalmente, alegre, brinca durante o caminho, mas não entra na escola ou na sala de aula e não se sente culpado com isso.

Quando os pais não conseguem convencer a criança a ir à escola e cedem, deixando de confrontar com a necessidade de ir à escola, a criança ou o adolescente se acalma e promete ir mais tarde. Nesse momento, fora dos ataques de ansiedade e de pânico, o fóbico se torna cooperativo e racionaliza seu medo (Ajuriaguerra \& Marcelli, 1991). Explica dizendo que os colegas zombam dele frequentemente 
e dizem não gostar dele, a criança pode afirmar também que o professor é severo demais e, quando isso acontece, os pais podem até mudá-lo de escola, o que não resolve o problema.

Com essas desculpas, muitas vezes as crianças e adolescentes com fobia escolar têm a ajuda dos pais e às vezes de profissionais para não frequentarem a escola. Principalmente quando as queixas são somáticas, os pais acabam compactuando com o filho e acreditam que ele não ir à escola seja o melhor, já que lá ele costuma passar mal (Sapienza, Schoen-Ferreira \& Aznar-Farias, 2003). Os pais acabam até buscando as tarefas dos filhos, que acompanham a matéria, na medida do possível, de casa. Então, novamente, diferenciando do absenteísmo, o adolescente com fobia escolar tem a permissão dos pais para faltarem e seus pais sabem o que eles estão fazendo quando não estão na escola. No absenteísmo, os pais acreditam que seus filhos estão na escola, quando na verdade estão cabulando as aulas.

Os adolescentes com fobia escolar dizem gostar da escola e costumam apresentar bom desempenho acadêmico (Grünspum, 1981; Papalia \& Olds, 2000; Sapienza, Schoen-Ferreira \& Aznar-Farias, 2003). Entretanto, com o passar do tempo e com a recusa em ir à escola, seu desempenho pode baixar e aí está mais uma razão para deixar de ir, ele não está acompanhando a turma. Mas é interessante que os adolescentes com fobia escolar não se opõem a fazer as tarefas de casa e sempre tentam recuperar o atraso (Ajuriaguerra \& Marcelli, 1991). Estes autores afirmam que ao invés de baixar seu rendimento acadêmico, o mais comum é até um superinvestimento, o adolescente passa dias inteiros estudando e mantém seu desempenho alto em relação aos seus colegas, mesmo com a ausência escolar prolongada. Entretanto, a literatura informa sobre muitos déficits que são instalados pela baixa frequência escolar.

\section{Evolução e Tratamento}

Ajuriaguerra e Marcelli (1991) afirmam que de 30 a $50 \%$ dos casos a fobia escolar tem uma evolução favorável tanto na reinserção às atividades escolares como na vida extraescolar. Em 30\% dos casos persistem algumas dificuldades e mesmo a fobia escolar, mas em um nível menos intenso e a reinserção às atividades escolares e extraescolares é satisfatória. Mas em alguns casos (20\%) a evolução é pouco favorável não só por persistir a fobia escolar, mas também pela existência de dificuldades de adaptação social.

O tratamento da fobia escolar deve ter caráter urgente, principalmente durante o início dos sintomas, quando ainda é relativamente fácil a remissão. Caso isso não aconteça, os sintomas podem ser irreversíveis ou o tratamento pode durar por anos sem que a criança consiga voltar a frequentar a escola, levando ao abando da escolarização, o que certamente prejudicará sua vida social e profissional (Grünspum, 1981).

O tratamento da fobia escolar pode envolver diversas modalidades, como terapia familiar, terapia individual, tratamento medicamentoso e, em casos mais graves, hospitalização. Ajuriaguerra \& Marcelli (1991) afirmam que a terapia individual é útil, porém seus resultados são lentos. Já a terapia familiar é indispensável, apesar de nem sempre aceita pela família. O tratamento mais adequado depende da consulta a um especialista, preferencialmente um psicólogo de abordagem cognitivo-comportamental (Petersen, 2011).

Em casos mais graves, a hospitalização e os antidepressivos podem ser coadjuvantes importantes para a redução dos sintomas ansiosos para que ocorra a participação ativa da criança ou adolescente e sua família no tratamento. Krook (1995) realizou um estudo com 24 crianças entre 06 e 07 anos para avaliar a efetividade do tratamento medicamentoso na fobia escolar e verificou que a medicação pode trazer benefícios ao tratamento. Porém, mudanças de comportamento organizadas com auxílio do psicólogo são fundamentais para garantir o retorno às atividades escolares e sua manutenção ao longo prazo.

$\mathrm{O}$ retorno às atividades escolares é fundamental para um bom prognóstico. Grünspum (1981) e Papalia e Olds (2000) acreditam que esse deve ser o foco inicial do tratamento da fobia escolar: buscar um retorno precoce e gradual à escola. Antes mesmo de vencer os sintomas, a criança deve ser estimulada a voltar às aulas, mesmo que esse não seja o desejo inicial da família (Grünspum, 1981). As mães superprotetoras podem boicotar o tratamento nessa primeira fase e aqui se faz importante a especialização do profissional que acompanha a 
família. Nesses casos, Grünspum (1981) alerta para que os psicólogos devem fornecer uma atenção especial à posição da mãe, a fim de compreender seus sentimentos e de identificar se ela está ou não contribuindo para a eficácia do tratamento. Comportamentos adequados, por exemplo, quando a criança ou o adolescente coopera e vai para aula sem problemas devem ser valorizados por pais e professores.

Os pais e os professores são, portanto, agentes importantes para que o indivíduo volte a frequentar as aulas sem problemas. Dessa forma, uma das primeiras ações do psicólogo ou do educador deve ser a de orientar a família, principalmente a mãe, sobre essa necessidade de a criança voltar à escola. Após o inicio do tratamento as crianças e adolescentes vão até a escola sem muita resistência, já que gostam da escola e têm vontade de frequentá-la. Durante o início do tratamento, principalmente as crianças pequenas podem começar pedindo que a mãe a acompanhe, o que pode ser permitido inicialmente (Grünspum, 1981). Depois a figura materna deve ser substituída por outra relacionada à escola e o tempo de permanência como acompanhante deve, aos poucos, ser reduzido. Dessa forma, professores e escola devem estar cientes do problema para que auxiliem nesse retorno.

Além de todos os problemas sociais, ocupacionais e de comportamento relacionados ao medo de ir à escola já apresentados, parece importante destacar que se esse medo não for tratado adequadamente, pode trazer consequências psicológicas graves, como a fobia social. Existem estudos indicado a fobia escolar, nos primeiros anos de vida, como preditora da fobia social na vida adulta (Vianna, Campos \& Landeira-Fernandez, 2009). Além disso, essas crianças procuram mais serviços de saúde, como atendimento médico por queixas somáticas atreladas à ansiedade (Asbahr, 2004)

\section{Conclusões}

A fobia escolar é um problema de grande relevância devido à frequência escolar ser condição obrigatória na cultura ocidental. Talvez por isso as pesquisas nessa área estejam aumentando, lentamente, mas aumentando. Com isso, o diagnóstico e a definição de tratamentos terapêuticos tornaram-se mais eficazes, o que favorece para um prognóstico favorável.

Crianças e adolescentes com fobia escolar, da mesma forma, como aqueles que matam aula (absenteísmo), sofrerão as mesmas consequências dos que a abandonam, pois perdem as oportunidades que a escola, como promotora da saúde, fornece para o desenvolvimento cognitivo, maturidade social e planejamento de futuro.

É papel dos pais e dos educadores conhecerem os diferentes transtornos psicológicos que podem acarretar em prejuízo no desempenho escolar da criança. Por isso, o objetivo do trabalho foi mostrar a existência da fobia escolar e algumas de suas características, além de ressaltar a existência de crianças e, especialmente, adolescentes que por diferentes razões não conseguem assistir às aulas. Ressalta-se a importância de profissionais que atuam com crianças e adolescentes compreenderem o problema, já que a fobia escolar pode ser preditora da Fobia Social.

\section{Referências}

Ajuriaguerra, J., \& Marcelli, D. (1991). Manual de psicopatologia infantil. $2^{\mathrm{a}}$. ed. Porto Alegre: Artes Médicas.

American Psychological Association (2013). DSM-5: manual diagnóstico e estatístico de transtornos mentais. Porto Alegre: ArtMed.

Asbahr, F.R. Transtornos ansiosos na infância e adolescência: aspectos clínicos e neurobiológicos. Jornal de Pediatria, 80 (2), 2004

Grünspum, H. (1981). Distúrbios neuróticos da criança. $4^{\mathrm{a}}$. ed. Rio de Janeiro: Atheneu.

Gutierrez, P. L. (1994). Dificuldades escolares. Em F. B. Assumpção, Psiquiatria da Infância e da Adolescência (pp. 251-255). São Paulo: Livraria e Editora Santos.

James A, Javaloyes A. Transtornos psicosociales y psicopatologia en la adolescencia. In: Carmina Saldaña. Detección y Prevención en el Aula de los Problemas del Adolescente. Colección Psicología. Madrid, Espanha: Ediciones Pirámide; 2001. p. 161-167.

Krook, I. V. (1995). Treatment of school phobia in children with specific developmental disorders of scholastic skills. European Neuropsychopharmacology, 5 (3), 365.

Méndez, F.X.; Olivares, J.; Bermejo, R.M. Características e tratamento dos medos, fobias e ansiedades específicas In: Caballo VE, Simón MA, editors. Manual de Psicologia 
Clínica Infantil e do Adolescente: transtornos gerais. Santos: Editora Santos; 2005.

Organização Mundial da Saúde (1993). Classificação de transtornos mentais e de comportamento da CID-10: descrições clínicas e diretrizes diagnósticas. Porto Alegre: Artes Médicas.

Papalia, D. E., \& Olds, S. W. (2000). Desenvolvimento humano. $7^{\mathrm{a}}$. ed. Porto Alegre: ArtMed.

Petersen, C.S. Evidências de efetividade e procedimentos básicos para terapia cognitivo-comportamental para crianças com transtornos de ansiedade. Revista Brasileira de Psicoterapia, 13(1), 39-50, 2011.

Sapienza, G., Schoen-Ferreira, T.H.S., \& Aznar-Farias, M. (2003, junho). Fobia escolar: características e estudo de caso. Trabalho apresentado em II Congresso Multidisciplinar de Neuropsicologia e Aprendizagem da Sociedade Brasileira de Neuropsicologia, Poços de Caldas, MG, Brasil.

VIANNA, Renata Ribeiro Alves Barboza; CAMPOS, Angela Alfano; LANDEIRA-FERNANDEZ, Jesus. Transtornos de ansiedade na infância e adolescência: uma revisão. Rev. bras.ter. cogn., Rio de Janeiro , v. 5, n. 1, jun. 2009 . Disponível em <http://pepsic. bvsalud.org/scielo.php?script $=$ sci_arttext\&pid $=\mathrm{S} 1808$ $56872009000100005 \& \operatorname{lng}=$ pt\&nrm $=\bar{i}$ iso $>$. acessos em 06 nov. 2014.

Submetido 09/2014

Aprovado 12/2014 